\title{
Morphometric Analysis of Radial Head and its Clinical Implications
}

\author{
A Akshaya ${ }^{1}$ and S Sangeetha ${ }^{2}$ \\ ${ }^{1}$ Department of Anatomy, Saveetha Dental College and Hospitals, \\ Saveetha institute of medical and technical sciences (SIMATS), \\ Saveetha university, Chennai-600 077, India \\ ${ }^{2}$ Department of Anatomy. Saveetha Dental College and Hospitals, \\ Saveetha institute of medical and technical science (SIMATS), \\ Saveetha university,Chennai-600 077, India
}

\section{ABSTRACT}

Radius is the bone of the forearm that is present on the lateral side.The head of the radius is a fundamental element for physiology and prosthetic stability of the elbow. Fracture of radial head constitutes about $\otimes$ rd of all elbow fractures. Now this is becoming more common because of pre existing comorbidities like osteoporosis. The aim of the study is to morphometrically analyse radial heads along with its clinical importance. For the study about 32 dry radius bone of unknown sex [right 16 and left 16] were collected from department of anatomy, saveetha dental college. Bones damaged or deformed are discarded from the purpose of the study. Anteroposterior diameter, transverse diameter, medial height and lateral height of radial head were measured using vernier callipers. The mean and standard deviation of these parameters were noted. The mean value of anteroposterior diameter of radial head for right is about $1.89 \mathrm{~mm}[\mathrm{SD}=0.169]$ and for left is $1.91 \mathrm{~mm}[\mathrm{SD}=0.177]$. The mean value of the transverse diameter of the radial head for the right side is $1.86 \mathrm{~mm}[\mathrm{SD}=0.161]$ and the left side is $1.87 \mathrm{~mm}[\mathrm{SD}=0.187]$. The mean value of medial height of radial head for right is $0.92 \mathrm{~mm}[\mathrm{SD}=0.090]$ and left is $0.82 \mathrm{~mm}[\mathrm{SD}=0.187]$. The mean value of lateral height of radial head for right is $0.84 \mathrm{~mm}[\mathrm{SD}=0.293]$ and left is $0.73 \mathrm{~mm}[\mathrm{SD}=0.113]$. Education of size and shape of radial head is essential in prosthesis and surgeries. This study concludes that both the right and left side of the radial head in all the parameters shows almost similar mean and standard deviation values. But this slight variation makes huge differences in anatomical orientations . Our study results are critical in making the radials anatomically and biomechanically suitable prosthesis.

KEY WORDS: FRACTURES, PROSTHESIS, ANTEROPOSTERIOR DIAMETER, TRANSVERSE DIAMETER, MEDIAL AND LATERAL HEIGHT.

\section{ARTICLE INFORMATION}

*Corresponding Author: visan8384@gmail.com

Received 4th Aug 2020 Accepted after revision 26th Sep 2020

Print ISSN: 0974-6455 Online ISSN: 2321-4007 CODEN: BBRCBA

Thomson Reuters ISI Web of Science Clarivate Analytics USA and Crossref Indexed Journal

\section{Clarivate
Analytics}

NAAS Journal Score 2020 (4.31) SJIF: 2020 (7.728)

A Society of Science and Nature Publication,

Bhopal India 2020. All rights reserved.

Online Contents Available at: http//www.bbrc.in/

Doi: $h t t p: / / d x . d o i . o r g / 10.21786 / b b r c / 13.8 / 152$ 


\section{INTRODUCTION}

Morphometry refers to a quantitative analysis of any structure,which includes both shape and size (ParésCasanova, 2017). It is basically measuring external shape and structure.Radius is the bone of the forearm, consisting of proximal end, distal end, shaft and tuberosity (SingH and SingH, 2019). Radial bone is important because it forms elbow and wrist joints.The radial head is disk shaped, concavity forming articulations and it is medially thicker present above radial tuberosity.The proximal end is approximately cylindrical shaped and articulates with elbow and radioulnar joints. The distal end is about quadrilateral shaped and consists of the articular surface for ulna, scaphoid and lunate bones.

About 2-6\% of the fracture occurs mostly in proximal ,distal end and neck of radius (Rayna et al., 2018). Radial head fractures represents the most common elbow fracture.They occur when axial load is applied on forearm, making radial head hit the humeral capitellum .Fractures that occurs more commonly Essex Lopresti fracture, Radial shaft fracture, Distal shaft fracture, Galeazzi fracture, Colles fracture,Barton's fracture (Al-Imam, 2016). The radius is ossified at three centres (shaft,two ends of the radius), which starts at the 8th week of intrauterine life.

Radial shortening,increased radial inclination ,dorsal angulations may cause major modification in elbow and wrist joints (Koslowsky et al., 2007). For animals with four legs the radius is the lower forelimb 's largest loadbearing bone. The function is similar in most terrestrial tetrapods but in some mammals (such as horses) it may be fused with the ulna and decreased or modified in animals with flippers or vestigial forelimbs (Romer and Parsons, 1977). Not only human pelvic bone is used for sex determination but also human radius shows some significance in sex discrimination (Mathivadani, Babu and Mohanraj, 2018). Previously our team had conducted numerous original studies (Pratha and Thenmozhi, 2016)-(Krishna and Babu, 2016) experimental studies (Seppan et al., 2018) and questionnaire based studies (Sriram, Yuvaraj and Others, 2015) over the past 5 years. Now the present study centred towards measuring the morphometric parameters and morphology of radial head and its clinical implications as it is necessary.

\section{MATERIAL AND METHODS}

The materials for this study contains 32 dry human radius of unknown sex collected from the department of anatomy, saveetha dental college.

\section{LIMITATIONS:}

- Incomplete ossified bone

- broken bone

- fractured bone / bone with any abnormalities.

Total of 32 bones in which 16 and left 16 were used and the following parameters were measured using manual vernier calliper.The parameters are anteroposterior diameter of radial head,transverse diameter,medial length and lateral length of radial head.

Anteroposterior Diameter: Distance between the anterior most point to the posterior point in the radial head.

Transverse Diameter: Distance between the medial border to the lateral in the radial head.

Medial Height: It is distance between radial lip ,neck and junction of medial surface.

Lateral Height: Distance between radial lip, neck and junction of lateral surface.
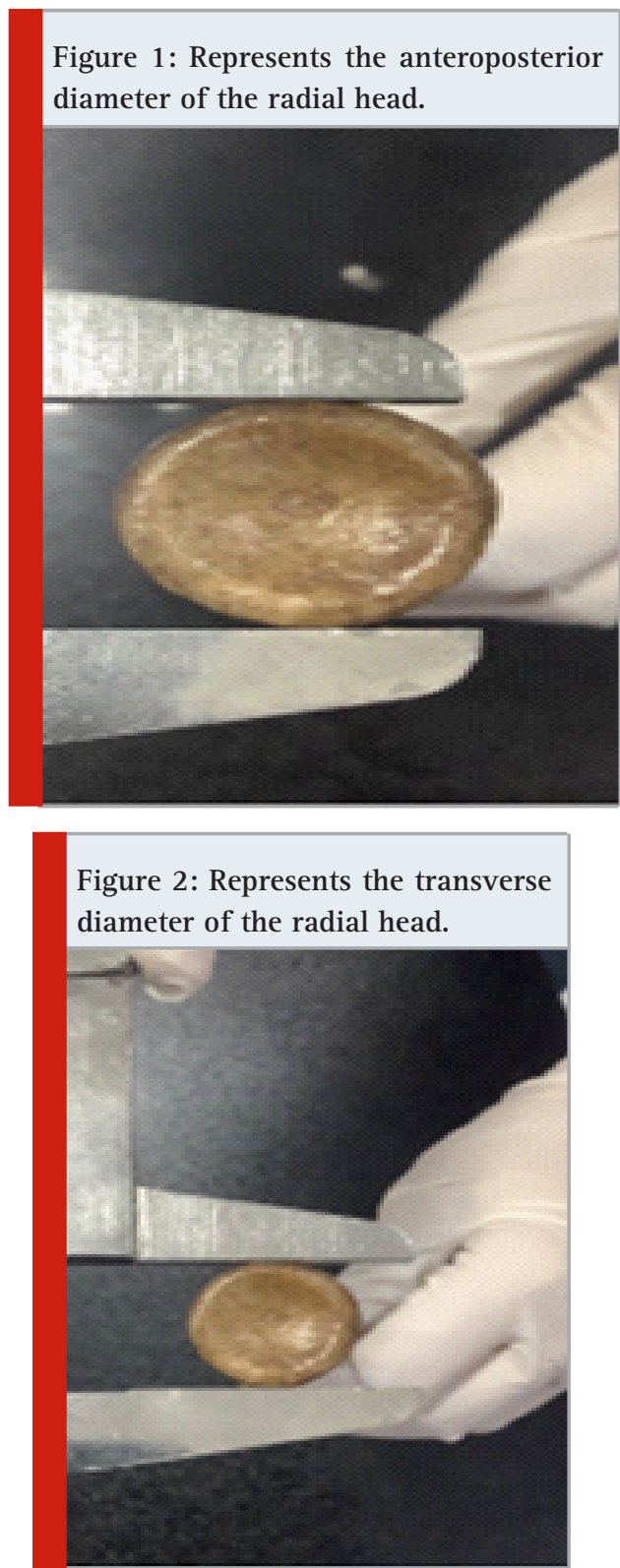

RESULTS AND DISCUSSION

Radius is a bone present in the lateral side of the forearm. Radial head forms two joint surfaces namely radioulnar and radiocapitellar joints. operative procedures of 
deformed radial head fractures fixed with plates and screws, when radial head is completely unreconstructable (Mishra et al., 2016) .Knowledge of size and shape of radial head is very necessary for radial head prosthetic procedures.
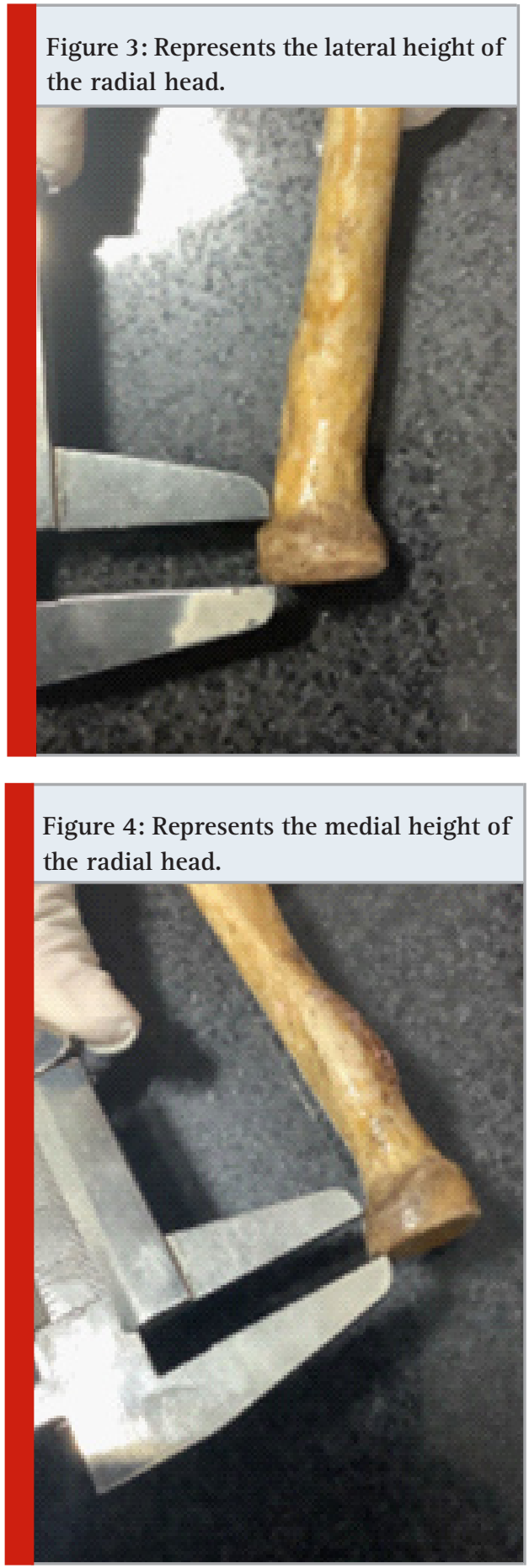

Archana Singh et al, found that mean and standard deviation of Anteroposterior diameter of radial diameter of right is about 20.442.45 and for left is about 20.59 2.16 , which shows slight variations only. Chandni Gupta et al, found that Transverse diameter of the radial head for right is about 1.890.21 and for left 1.82 0.21, which also shows very slight variations between right and left values (Gupta et al., 2015). A Brite sangaya rayna et al , found that the mean values of medial height for both right and left is about 0.6 and the mean for lateral height for right is about 0.32 and for left is 0.30 .medial surface of head is more thicker than lateral surface. Suraj ethiraj et al., found that the mean values of medial height and lateral height is about $0.91 \mathrm{~cm}$ and $0.73 \mathrm{~cm}$ (Ethiraj, Jyothi and Shetty, 2019).

Figure 5: Bar graph represents the mean value of anteroposterior diameter of radial head. $\mathrm{X}$ axis represents the side of the radius bone and $Y$ axis represents the mean value of anteroposterior diameter of radial head in $\mathrm{mm}$. Red(Right) and Blue(Left). The mean value of anteroposterior diameter of the radial head of the left bone is more than the right bone.

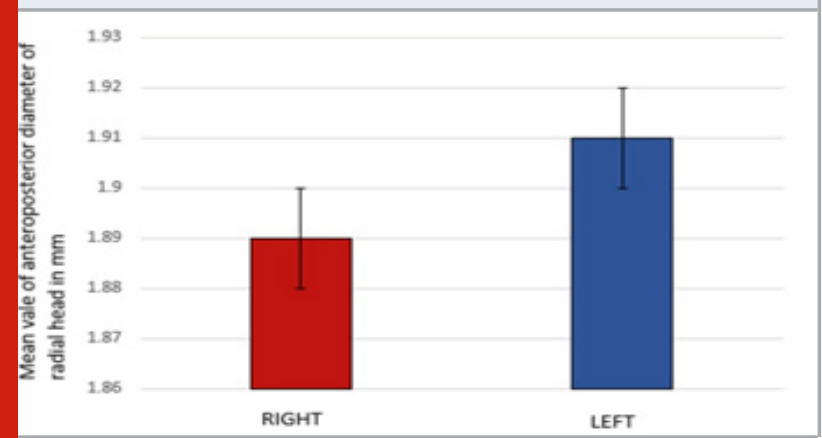

Figure 6: Bar graph represents the mean value of transverse diameter of radial head.X axis represents the side of the radius bone and $\mathrm{Y}$ axis represents the mean value of transverse diameter of radial head in $\mathrm{mm}$. Red(Right) and Blue(Left). The mean value of transverse diameter of the radial head of the left bone is more than the right bone.

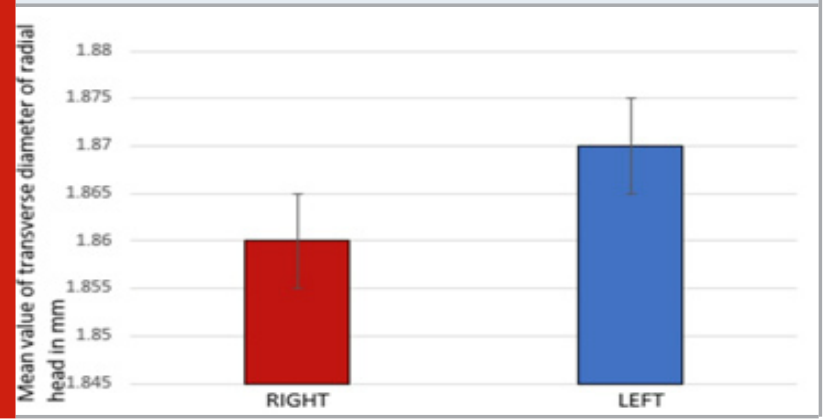

Soorya sridhar et al., found that mean and standard deviations values for anteroposterior diameter is about $19.27 \mathrm{~mm}, 1.79$ for right and $18.74 \mathrm{~mm}, 2.71$ for left side (Sridhar et al., 2015). Muna Kadel et al., found that the mean values of lateral and medial height is $0.76 \mathrm{~cm}$ and $0.91 \mathrm{~cm}$ respectively and also mean values for anteroposterior diameter and transverse diameter is about $2.09 \mathrm{~cm}$ and $2.02 \mathrm{~cm}$ (Kadel and Thapa, 2020). In our study, the results were based on readings obtained from original bone. But in some studies morphometric studies were done by using computer tomography images with two and three dimensional resonance (Mahaisavariya et al., 2004). 
Figure 7: Bar graph represents the mean value of medial height of radial head.X axis represents the side of the radius bone and $\mathrm{Y}$ axis represents the mean value of medial height of radial head in mm. Red(Right) and Blue(Left). The mean value of the medial height diameter of the radial head of the left bone is more than the right bone.

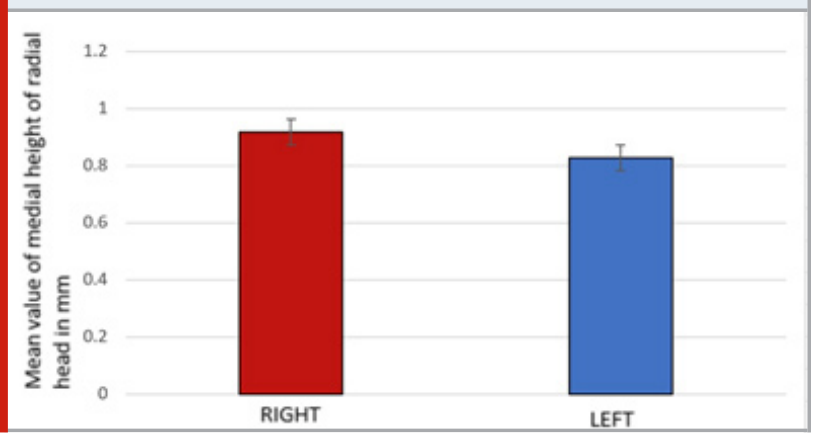

\section{CONCLUSION}

In our study, we analysed the morphometric parameters of head of radius. From the results, it was evident that there is no much difference between right and left dimension among all the selected parameters. More sample size may help to find out precise findings. Knowledge about slight variations in these parameters is also very important. Because the radial head involves articulation with the humerus and ulnar bone to form the elbow joint.

\section{ACKNOWLEDGEMENTS}

The authors would like to acknowledge the help and support rendered by the Department of Anatomy and the Management of Saveetha Dental College and Hospitals for their constant assistance with the research.

Conflict of Interest: None declared.

\section{REFERENCES}

Al-Imam, A. (2016) 'Medio-lateral inclination of proximal and distal articular surface of the radius', Asian Journal of Medical Sciences. nepjol.info, 7(5), pp. 117-123.

Ethiraj, S., Jyothi, K. C. and Shetty, S. (2019) 'A STUDY OF MORPHOLOGY AND MORPHOMETRY OF PROXIMAL END OF DRY RADIUS BONES WITH ITS CLINICAL IMPLICATIONS', Int J Anat Res. pdfs. semanticscholar.org, 7(3.1), pp. 6712-6716.

Gupta, C. et al. (2015) 'A morphological and morphometric study of proximal and distal ends of dry radii with its clinical implications', Biomedical journal. biomedj.cgu. edu.tw, 38(4), pp. 323-328.

Kadel, M. and Thapa, T. P. (2020) 'Study of the Head of Human Dry Radii in a Medical College of Nepal: A Descriptive Cross-sectional Study', JNMA; journal of the Nepal Medical Association. search.ebscohost.com,
Figure 8: Bar graph represents the mean value of lateral height of radial head. $X$ axis represents the side of the radius bone and $\mathrm{Y}$ axis represents the mean value of lateral height of radial head in $\mathrm{mm}$. Red (Right) and Blue(Left). The mean value of the lateral height diameter of the radial head of the left bone is more than the right bone.

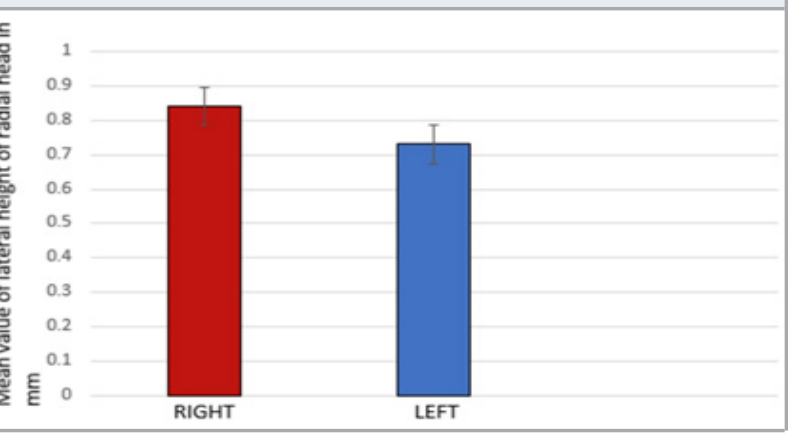

58(223), pp. 141-143.

Koslowsky, T. C. et al. (2007) 'Morphometric parameters of the radial neck: an anatomical study', Surgical and radiologic anatomy: SRA. Springer, 29(4), pp. 279-284.

Krishna, R. N. and Babu, K. Y. (2016) 'Estimation of stature from physiognomic facial length and morphological facial length', Research Journal of Pharmacy and Technology. A \& V Publications, 9(11), pp. 2071-2073.

Mahaisavariya, B. et al. (2004) 'Morphology of the radial head: a reverse engineering based evaluation using three-dimensional anatomical data of radial bone', Proceedings of the Institution of Mechanical Engineers. Part H, Journal of engineering in medicine. journals. sagepub.com, 218(1), pp. 79-84.

Mathivadani, V., Babu, K. Y. and Mohanraj, K. G. (2018) 'Determination of sex from radial tuberosity and shaft of radius-A morphometric study using long bone', Drug Invention Today. search.ebscohost.com, 10(10). Available at: https://bit.ly/3i7Pt10

Mishra, P. K. et al. (2016) 'Morphometry of distal end radius in the Indian population: A radiological study', Indian journal of orthopaedics. Springer, 50(6), pp. 610-615.

Parés-Casanova, P. M. (2017) 'Introductory ChapterMorphometric Studies: Beyond Pure Anatomical Form Analysis', New Insights into Morphometry Studies. BoD--Books on Demand, p. 1.

Pratha, A. A. and Thenmozhi, M. S. (2016) 'A study of occurrence and morphometric analysis on meningo orbital foramen', Research Journal of Pharmacy and Technology. A \&t V Publications, 9(7), pp. 880-882. Rayna, A. et al. (2018) 'Morphometric Study of Proximal and Distal End of Radius and its Clinical Significance', Journal of clinical and diagnostic research: JCDR. 
search.ebscohost.com, 12(9). Available at: https://bit. ly/3idRolw

Romer, A. S. and Parsons, T. S. (1977) 'The Vertebrate Body. Philadelphia, PA: Holt-Saunders International'. ISBN 0-03-910284-X.

Seppan, P. et al. (2018) 'Therapeutic potential of Mucuna pruriens (Linn.) on ageing induced damage in dorsal nerve of the penis and its implication on erectile function: an experimental study using albino rats', The aging male: the official journal of the International Society for the Study of the Aging Male. Taylor \&
Francis, pp. 1-14.

SingH, A. and SingH, A. (2019) 'A Morphometric Study of Head of Radius and its Clinical Implication in Radial Head Prosthesis', studies [Table/Fig-1]. ijars.net, 4, p. 11.

Sridhar,S. et al.(2015) [No title]. Available at: https:// bit.ly/2ScHCoY

Sriram, N., Yuvaraj, S. and Others (2015) 'Effects of Mobile Phone Radiation on Brain: A questionnaire based study', Research Journal of Pharmacy and Technology. A \& V Publications, 8(7), pp. 867-870. 